\title{
Farklı Tarihlerde Hasat Edilen Şeker Pancarı Genotiplerinin Verim ve Verim Unsurlarının Belirlenmesi
}

\author{
*Fırat SEFAOĞLU Canan KAYA Aydın KARAKUŞ \\ Doğu Anadolu Tarımsal Araştırma Enstitüsü Müdürlüğü, Erzurum \\ *Sorumlu yazar e-posta (Corresponding author e-mail): firat.sefaoglu@tarim.gov.tr
}

\section{Öz}

Bu araştırma farklı zamanlarda hasat edilen şeker pancarı kökgövdelerinde verim ve verim unsurlarını belirlemek amacı ile 2014 yılında Erzurum ekolojik şartlarında, Tesadüf Blokları Deneme Deseni'ne göre, dört tekrarlanmalı olarak yürütülmüştür. Denemede, şeker pancarı kökgövdeleri 3 farklı tarihte (Ekim ayının 1. haftası, Ekim ayının 3. haftası ve Kasım ayının ilk haftası ) hasat edilmiştir. Araştırmada kök verimi(kg/da), şeker oranı (\%), şeker verimi (kg/da), kuru madde ve usare safiyeti gibi parametreler incelenmiştir. Çalışmada şeker verimi hasat tarihlerine göre, kök verimi ise hasatların birleştirilmesi ile yapılan istatistikî analiz sonucunda önemli çıkmıştır. Ortalama en yüksek kök verimi $(8045.62$ kg/da), şeker verimi (1323.50 kg/da) ve şeker oranı (\%18.8) Kasım ayının ilk haftası yapılan hasattan elde edilmiştir. Araştırma sonuçlarımıza göre Erzurum koşullarında şeker pancarında uygun hasat tarihi olarak Kasım ayının ilk haftası ön plana çıkmıştır.

Anahtar Kelimeler: Şeker pancarı, Beta vulgaris saccharifera, kök verimi, şeker oranı

\section{The Determination of Yield and Yield Components of Sugarbeet Genotypes (Beta vulgaris saccharifera L.) Harvested at Different Dates}

\begin{abstract}
This research was carried out in four replications that harvested at different times in order to determine yield and yield components of root-body sugar beet, according to the Randomized Block Pattern, the ecological conditions in Erzurum in 2014. In the experiment, sugar beet's root-body were harvested in 3 different dates ( $1^{\text {st }}$ week of October, the $3^{\text {rd }}$ week of October and first week of November). In the research was investigated such as parameters root yield $(\mathrm{kg} / \mathrm{ha})$, sugar rate $(\%)$, sugar yield $(\mathrm{kg} / \mathrm{ha})$, dry matter and usare purity. The sugar yield among the harvest date is significant $(P<0.05)$, and root yields was determined compared to the combined harvest date. Average highest root yield $(8045.62 \mathrm{~kg} / \mathrm{ha})$, sugar yield $(1323.50$ $\mathrm{kg} / \mathrm{ha}$ ), and sugar ratio (18.8\%) was gained from harvest in the first week of November. According to our research results, at sugar beet suitable harvest date is the first week of November in Erzurum conditions.
\end{abstract}

Keywords: Sugar beet, Beta vulgaris saccharifera, root yield, sugar ratio

\section{Giriş}

S eker Dünya'da şeker kamışından ülkemizde ise şeker pancarından elde eđ̛ilen bir tarla bitkisidir. Dünyada üretilen şekerin \%80'i kamıştan \%20'si pancardan elde edilmekle birlikte, ülkelerin coğrafi konumları asıl belirleyici rolü oynamaktadır Şeker kamışı tropik iklim kuşağında yetişirken, şeker pancarı (Beta vulgaris saccharifera L.), kuzey yarım kürede ülkemizin de bulunduğu $30^{\circ}$ güney- $60^{\circ}$ kuzey enlemleri arasında yer alan değişik iklim kuşakları ve bölgelerde yetişmektedir (Gencer, 1988; Morillo-Velarde, 1993).
Gece-gündüz sıcaklıkları arasında belirli fark isteyen, karasal iklime yakın iklim değerlerinde sulanmak şartıyla iyi yetişebilen şeker pancarı bitkisi ülkemiz için başlıca şeker kaynağı olmuştur. Şeker pancarı Erzurum'da 2014 yılında 24.576 da alanda toplam 100.693 ton üretimi yapılmıştır (Anonymus 2014). Ortalama verim, Türkiye, ve Erzurum'da sırasıyla 5666 kg/da, $4106 \mathrm{~kg} / \mathrm{da}$, (Anonymous 2014).

Ülkemizde şeker pancarı hasadı genel olarak karasal iklimin hâkim olduğu bölgeler ile geçit bölgelerinde 15-20 Eylülde başlamaktadır. 
Vejetasyon periyodunun kısa olması, şeker pancarı hasadının erken ya da geç yapılması verimde düşüşlere sebep olabilmektedir. Hasat zamanı ile yapılan çalışmalarda Held et al. (1994), 4 yıl süre ile yaptıkları çalışma sonucunda 10-16 Eylül, 17-23 Eylül, 24-30 Eylül, 1-8 Ekim, 9-16 Ekim ve 17-24 Ekim tarihleri arasında ortalama olarak sırasıyla 5362, 5535, 5733, 5930, 6153 ve $6350 \mathrm{~kg} / \mathrm{da}$, Akınerdem ve ark. (1996) Konya'da 15 Eylül, 1 Ekim, 15 Ekim ve 1 Kasım'da yaptıkları hasatta sırası ile3764, 4053, 4198, 4142 kg/da, Jozefyová ve ark. (2003) Eylül ve Ekim sonundaki hasatlardan 5859 ve 6994 kg/da, Öztürk ve ark. (2008) ise 18 Eylül, 2 Ekim, 18 Ekim ve 1 Kasım hasatlarından sırasıyla $3668,4371,4855$ ve $4758 \mathrm{~kg} / \mathrm{d}$, Sefaoğlu ve ark. (2013) Erzurum'da ekim ayının ilk haftası, üçüncü haftası ve kasım ayının ilk haftası yapmış oldukları hasatta sırası ile 5686.4, 6962.9 ve 7427.1 kg/da (Ülker ve ark. 2013; Çatal 2013) yapmış oldukları çalışmada en yüksek kök vermi ve şeker verimlerini sırası ile $5295-9926.5 \mathrm{~kg} / \mathrm{da}$ ve 837-1869.3 $\mathrm{kg} / \mathrm{da}$ arsında olduğunu bildirmişlerdir. Erzurum şartlarında 2014 yılında yürütülen bu çalışmada, genotiplerden kökgövde ve şeker verimi yüksek olanlar tespit edilerek şeker pancarında uygun hasat zamanının belirlenmesi amaçlanmıştır.

\section{Materyal ve Yöntem}

Deneme materyali olarak tohumculuk şirketlerinden [BETA (Idaho, Tomcat, Eldorado, Zanzibar, Mohican, Rodeo, Lizard, SR-485);
KWS (Maden, Aranka, Sandrina, Esperia, 9R27); SYNGENTA (Turbata, Sentinel)] temin edilen 15 adet çeşit kullanılımıştır.

Araştırma, Doğu Anadolu Tarımsal Araştırma Enstitüsü Müdürlüğü deneme alanında "Tesadüf Blokları Bölünmüş Parseller deneme deseni 'ne göre yürütülmüş ve hasat tarihleri ana parsellere çeşitler ise alt parsellere gelecek şekilde dört tekerrürlü olarak kurulmuştur. Ekimde parsel alanı $10 \times 0.45 \times 3=13.5$ (3 sıralı, sıra arası/sıra üzeri mesafe $0.45 \mathrm{~cm} / 0.20 \mathrm{~cm}$, sıra uzunluğu 10 $\mathrm{m}$ ) hasatta ise $8.80 \times 0.45 \times 3=11.88 \mathrm{~m}^{2}$ (sıraların her iki başından 3'er bitki kenar tesiri olarak sökülecek) olarak kurulmuştur. Hasatta 132 adet pancar değerlendirmeye alınmıştır. Deneme alanı 2014 ilkbaharında uygun herbisitle ilaçlanarak 02 Nisan 2014 tarihinde mibzerle ekim yapılmıştır. Araştırma süresince intiyaca göre, çapalama ve sulama (yağmurlama) gibi kültürel işlemler yapılmıştır.

Deneme alanına toprak tahlilleri yapıldıktan sonra gerekli görülen gübre form ve dozları.uygulanmıştır. Araştırmada kullanılan şeker pancarı çeşitleri 3 farklı tarihte (Ekim ayının ilk haftası, Ekim ayının üçüncü haftası, Kasım ayının ilk haftası) hasat edilmiştir.

Çalışmada, 2014 yılında Nisan- Eylül ayları arasında geçekleşen ortalama hava sıcaklıkları uzun yıllar değerlerinin biraz üzerinde gerçekleşmiştir (Anonymous 2014). Araştırmada, 2014'de şeker pancarının çıkış ve gelişme

Çizelge 1. Erzurum/merkez lokasyonu deneme alanına ait 2014 yılı İklim verileri

Table 1. Meteorological data of Erzurum/central location experimental site, 2014

\begin{tabular}{|c|c|c|c|c|c|c|c|c|}
\hline İklim Özellikleri & Nisan & Mayıs & $\begin{array}{c}\text { A } \\
\text { Haziran }\end{array}$ & $\begin{array}{c}\text { I a r } \\
\text { Temmuz }\end{array}$ & Ağustos & Eylül & Ekim & $\begin{array}{l}\text { Vejetasyon } \\
\text { ortalaması }\end{array}$ \\
\hline Toplam yağış, mm & 31.6 & 88.6 & 21.6 & 27.8 & 3.6 & 47.7 & & 36.8 \\
\hline Nispi nem, $\%$ & 64.5 & 68.7 & 54.9 & 46.9 & 39.6 & 48.3 & & 53.8 \\
\hline Ortalama sıcaklık, ${ }^{\circ} \mathrm{C}$ & 7.5 & 11.3 & 15.3 & 20.6 & 21.4 & 15.7 & & 15.3 \\
\hline En yüksek sıcaklık ${ }^{\circ} \mathrm{C}$ & 20.8 & 23.9 & 28.8 & 33.4 & 33.1 & & & \\
\hline En düşük sıcaklık ${ }^{\circ} \mathrm{C}$ & -10.2 & -3.2 & 0.8 & 6.0 & 7.6 & & & \\
\hline \multicolumn{9}{|c|}{ Uzun Yıllar Ortalaması 1954-2013 } \\
\hline Toplam yağış, mm & 53.4 & 68.8 & 46.6 & 25.5 & 16.5 & 21.6 & & 38.73 \\
\hline Ortalama sıcaklık, ${ }^{\circ} \mathrm{C}$ & 5.4 & 10.6 & 14.9 & 19.3 & 19.3 & 14.5 & & 14.0 \\
\hline En yüksek sıcaklık ${ }^{\circ} \mathrm{C}$ & 26.5 & 29.1 & 32.2 & 35.6 & 36.5 & 33.3 & & 32.2 \\
\hline En düssük sıcaklık ${ }^{\circ} \mathrm{C}$ & -22.4 & -7.1 & -5.6 & -1.8 & -1.1 & -6.8 & & -7.5 \\
\hline
\end{tabular}

Çizelge 2. Erzurum/merkez lokasyonu deneme alanına ait 2014 yılı toprak analiz sonuçları Table 2. Soil analysis results of Erzurum/central location experimental site, 2014

\begin{tabular}{lcc}
\hline Analizin Adı & 2014 & Değerlendirme \\
\hline Saturasyon ,\% & 48 & Tınlı \\
pH & 7.32 & Çok hafif alkali \\
EC & 2.27 & Tuzsuz \\
Tuz & 0.07 & Tuzsuz \\
Kireç, \% & 0.65 & Az kireçli \\
Org.mad. \% & 1.29 & Az \\
Fosfor, kg/da & 7.76 & Yüksek \\
Potasyum, kg/da & 187 & Yüksek \\
\hline
\end{tabular}


dönemi olan Nisan, Mayıs, Haziran ve Temmuz aylarında gerçekleşen yağış miktarları ise uzun yıllar ortalamasının bir hayli gerisinde kalmıştır.

Tınlı bünyeye sahip olan araştırma alanı toprağının $\mathrm{pH}$ değeri 7.32 olup çok hafif alkalin karakterdedir. $2.27 \mu \mathrm{S} / \mathrm{cm}$ ile elektriksel iletkenlik değeri ile tuzluluk problemi yoktur (Steole 1967). Deneme toprakları \%0.65 $\mathrm{CaCO}^{3}$ içeriği ile az kireçli olup, organik madde yönünden $(\% 1,1.29)$ ise fakirdir (Ülgen ve Yurtseven 1984).

\section{Bulgular ve Tartışma}

\section{Kökgövde Verimi}

Erzurum koşullarında farklı şeker pancarı genotipleri ile yürütülen çalışmada 1. 2. ve 3. hasat tarihlerinde elde edilen ortalama kökgövde verimleri ve genotip* hasat zamanına ait ortalama kökgövde verimleri Çizelge 3. ile verilmiştir. Ekim ayının ilk haftasında yapılan 1. hasatta verim $6768.8-5527 \mathrm{~kg} / \mathrm{da}$ arasında değişmiş̧ir. En yüksek ve en düşük verimler 2 . hasat tarihinde ise $7475.8-6266.8 \mathrm{~kg} /$ arasında belirlenmişken kasım ayının ilk haftasında yapılmış olan 3 . hasat tarihinde en yüksek verim $8045.6 \mathrm{~kg} / \mathrm{da}$, en düşük verim ise 5586.9 $\mathrm{kg} / \mathrm{da}$ olarak tespit edilmiştir. Yapılan istatistiksel değerlendirmede genotip* hasat zamanına ait kökgövde verimleri önemli $(p<0.05)$ çıkmıştır ve en yüksek ortalama kök verimi $7430.1 \mathrm{~kg} / \mathrm{da}$ olarak belirlenmiştir. Farklı hasat zamanlarından alınan ortalama verimler ise (Şekil 1.) istatistikî olarak önemsiz bulunmuştur ve 2 . hasat tarihinde $6781.8 \mathrm{~kg} / \mathrm{da}$ ile en yüksek ortalama verim elde edilmiştir.

Hasat döneminde yağışlı dönemin başlamasıla birlikte toprakta biriken aşırı suyun kökgövde'ler tarafından absorbe edildiğini dolayısı ile kökgövde veriminin artıığını bildirmişlerdir. Benzer şekilde, bu araştırmada da, kökgövde verimi üzerine iklimin

Verim

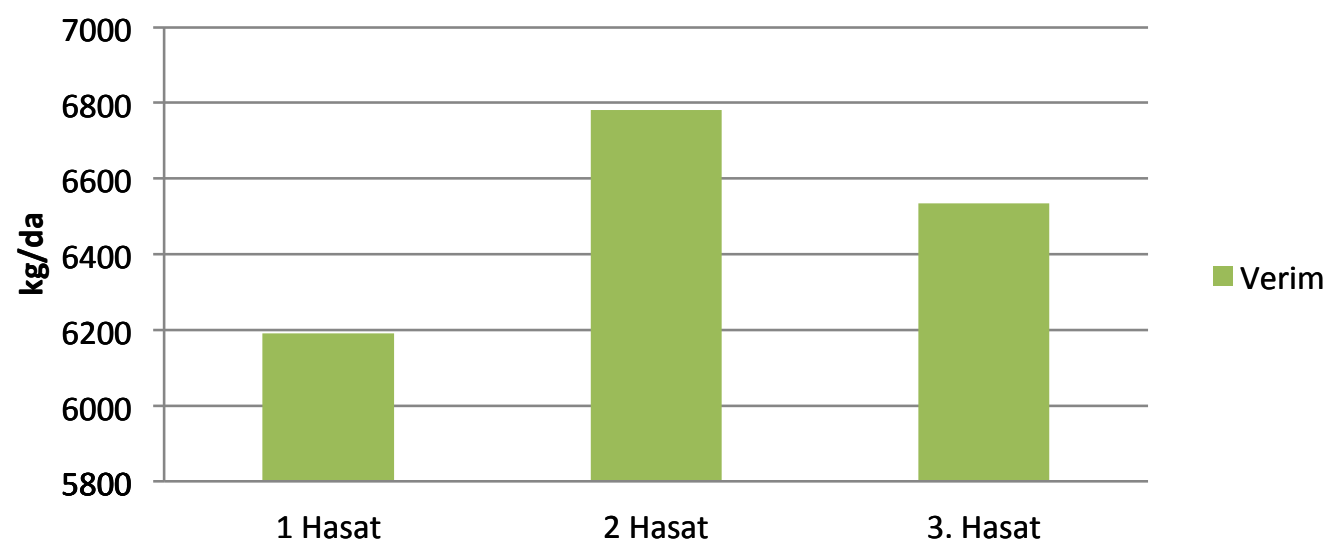

Şekil 1. Genotiplerden farklı hasat zamanlarında alınan ortalama verimler Figure 1. Average yields of genotips on different consequent harvests

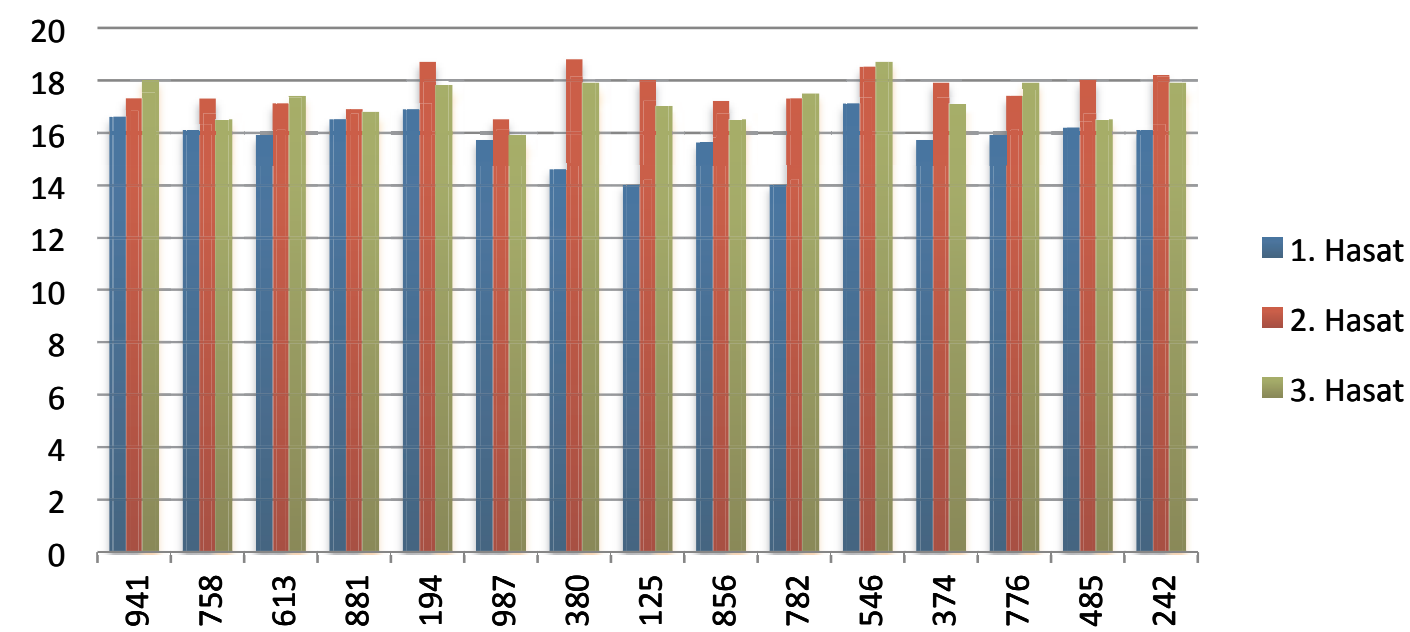

Şekil 2. Şeker pancarı genotiplerinde farklı hasat tarihlerinde belirlenen digestion oranları Figure 2. Digestion ratios of sugarbeet genotypes on consequent harvests 
özellikle de hasat döneminde (Eylül-Kasım) düşen yağış miktarlarının etkisinin büyük olduğu düşünülmektedir. Çakmakçı ve Oral'ın (2001) yaptığı bir araştırmada, ekim tarihinin Nisan başından Mayıs sonuna kadar geciktirilmesi durumunda, geç kalınan her bir gün için kök verimi dekara $70.3 \mathrm{~kg}$ azalmıştır. Hasadın 26 Eylül'den 16 Ekim'e ertelenmesiyle kök verimi $631 \mathrm{~kg} / \mathrm{da}$ düzeyinde artmıştır. Benzer çalışmalarda da araştırıcılar hasat zamanının geçikmesi ile kökgövde veriminin belirli bir noktaya kadar arttığını daha sonra tekrardan düştüğünü (Held et al. 1994; Akınerdem ve ark. 1996; Jozefyova ve ark. 2003; Öztürk ve ark.2008; Sefaoğlu ve ark. 2013) bildirmişlerdir

\section{Şeker Oranı}

Araştırmanın yürütüldüğü yılda farklı hasat tarihlerinde belirlenen digestion oranları arasındaki fark istatistikî olarak önemsiz bulunmuştur (Şekil 2.) Denemenin gerçekleştiği yılda (2014) En yüksek digestion oranı 2.hasat tarihinde $\% 18.8$ en düşük digestion oranı ise 1.hasat tarihinde \% 14.00 elde edilmiştir. Araştırmacıların 1987-2013 yılları arasında yapmış oldukları çalışmalarda şeker oranını \%10.15-21.99 arasında bulmuşlardır (Bilgin 1987; Akınerdem ve ark. 1996; Kurtcebe 1999). Araştırmada, farklı hasat zamanlarında ki şeker oranı değeri Ekim ayının ilk haftasından kasım ayının ilk haftasına gidildikçe arttığı görülmektedir. Bu durumu Tayfur ve Abacı (2002), 30 Eylül 20 Ekim ve 9 Kasım tarihlerinde yapmış oldukları hasatlarda sırası ile $15.7,16.3$ ve 15.3 şeker oranı elde ettiklerini ve şeker oranının belli bir noktaya kadar arttığını sonra artmadığını ve olgunluk dönemine geçtiğini bildirmiştir.

\section{Şeker Verimi}

Şeker pancarı genotiplerinden üç farklı hasat tarihinde tespit edilen ham şeker verimleri ve genotip*hasat zamanına ait ortalama şeker verimleri Çizelge 4 . ile verilmiştir. Yapılan istatistiksel değerlendirmede hasat

Çizelge 4. Şeker pancarı genotiplerinde farklı hasat tarihlerinde belirlenen Şeker verimleri Table 4. Sugar yields of sugarbeet genotypes on consequent harvests

\begin{tabular}{|c|c|c|c|c|c|c|c|c|}
\hline \multirow{2}{*}{$\begin{array}{l}\text { Genotip } \\
941\end{array}$} & \multicolumn{2}{|c|}{$\begin{array}{c}\text { 1. Hasat } \\
\text { Şeker verimi } \\
\text { kg/da }\end{array}$} & \multicolumn{2}{|c|}{$\begin{array}{c}\text { 2. Hasat } \\
\text { Şeker verimi, } \\
\text { kg/da }\end{array}$} & \multicolumn{2}{|c|}{$\begin{array}{c}\text { 3. Hasat } \\
\text { Şeker verimi, } \\
\text { kg/da }\end{array}$} & \multicolumn{2}{|c|}{$\begin{array}{c}\text { Ortalama } \\
\text { Şeker Verimi } \\
\text { (kg/da) }\end{array}$} \\
\hline & 1059.7 & $a-b$ & 1264.3 & $a-b$ & 1290.4 & $a-b$ & 1204.8 & $a-b$ \\
\hline 758 & 930.4 & $b-d$ & 1120.2 & $c-d$ & 1029.6 & $c-e$ & 1026.7 & $f-g$ \\
\hline 613 & 949.7 & $a-c$ & 1135.8 & $b-d$ & 1136.2 & $a-e$ & 1073.9 & $d-g$ \\
\hline 881 & 1063.3 & a & 1171.0 & $a-d$ & 1173.7 & $a-d$ & 1136.0 & $a-e$ \\
\hline 194 & 936.8 & $a-c$ & 1183.4 & $a-c$ & 1092.4 & $b-e$ & 1070.9 & $d-g$ \\
\hline 987 & 968.2 & $a-c$ & 1034.0 & d & 956.4 & e & 986.2 & $\mathrm{~g}$ \\
\hline 380 & 879.9 & $c-d$ & 1270.2 & $a-b$ & 1106.5 & $b-e$ & 1085.5 & $c-f$ \\
\hline 125 & 799.3 & d & 1194.9 & $a-c$ & 1092.8 & $b-e$ & 1029.0 & $f-g$ \\
\hline 856 & 1055.9 & $a-b$ & 1287.3 & a & 1323.5 & a & 1222.3 & a \\
\hline 782 & 891.9 & $c-d$ & 1273.4 & $a-b$ & 1118.1 & $a-e$ & 1094.5 & $c-f$ \\
\hline 546 & 1038.7 & $a-b$ & 1245.7 & $a-c$ & 1218.4 & $a-c$ & 1167.6 & $a-c$ \\
\hline 374 & 1047.4 & $a-b$ & 1259.5 & $a-c$ & 1038.6 & $c-e$ & 1115.2 & $b-f$ \\
\hline 776 & 1059.4 & $a-b$ & 1209.8 & $a-c$ & 1216.5 & $a-c$ & 1161.9 & $a-d$ \\
\hline 485 & 998.2 & $a-c$ & 1149.8 & $a-d$ & 1140.7 & $a-e$ & 1096.2 & $c-f$ \\
\hline 242 & 1001.0 & a-c & 1179.0 & $a-c$ & 1000.1 & d-e & 1060.0 & $e-g$ \\
\hline ORT. & 978.7 & & 1198.5 & & 1128.9 & & 1102.9 & \\
\hline ÇEŞIT & * & & $* *$ & & $* *$ & & * & \\
\hline Tekerrür & * & & -- & & ** & & - & \\
\hline LSD & 131.3 & & 140.5 & & 207.9 & & 92.6 & \\
\hline CV & 9.4 & & 8.2 & & 12.9 & & 10.4 & \\
\hline
\end{tabular}

Çizelge 5. Genotiplerden farklı hasat zamanlarında alınan ortalama ham şeker verimleri

Table 5. Average crude sugar yields of sugarbeet genotypes on consequent harvests

\begin{tabular}{ccc}
\hline Hasat Zamanı & Ham şeker verimi \\
\hline 2 & 1198.5 & $\mathrm{~A}$ \\
3 & 1128.9 & $\mathrm{~B}$ \\
1 & 978.6 & $\mathrm{~B}$ \\
\hline Çeşit & ${ }^{*}$ & \\
Zaman & ${ }^{* *}$ & \\
CV & 10.4 \\
LSD & 118.0 \\
\hline
\end{tabular}


Sefaoğlu et al. "The Determination of Yield and Yield Components of Sugarbeet Genotypes (Beta vulgaris saccharifera L.) Harvested at Different Dates"

zamanlarının ham şeker verimleri üzerine etkisi istatistikî olarak önemli çıkmıştır. Farklı hasat tarihlerinde genotiplerin ham şeker verimlerinin 1323.50-799.29 kg/da arasında değiştiği belirlenmiştir. Ekim ayının ilk haftasında yapılan 1. hasatta şeker verimi 1063.33-799.29 kg/da arasında değişmiştir. En yüksek ve en düşük şeker verimleri 2. hasat tarihinde ise 1287.34$1034.04 \mathrm{~kg} / \mathrm{da}$ arasında tespit edilmiştir. 3 . hasat kasım ayının ilk haftasında yapılmış ve en yüksek şeker verimi $1323.50 \mathrm{~kg} / \mathrm{da}$ olarak belirlenmiştir. Yapılan istatistiksel değerlendirmede Genotip*hasat zamanına ait şeker verimleri $(p<0.01)$ önemli çıkmıştır ve en yüksek ortalama şeker verimi 1222.26 kg/da olarak elde edilmiştir. Farklı hasat zamanlarından alınan ortalama verimler (Çizelge 5.) istatistikî olarak $(p<0.01)$ önemli çıkmış ve 2 . hasat tarihinden en yüksek ortalama verim elde edilmiştir.

Erzurum yöresinde pancar kök verimi ve şeker oranında Eylül sonuna kadar görülen hızıı artışın, Ekim ayı sonuna kadar devam ettiği belirlenmiştir. Dondurucu düşük sıcaklık meydana gelmediği ve fotosentez devam ettiği müddetçe hasadın gecikmesiyle kök ve şeker verimi ile birlikte safiyet ve şeker oranının da arttığı ortaya konulmuştur. Yetişme periyodu uzunluğu veya ekim ile hasat tarihi arasındaki günlerin sayısı arttıkça pancar verim ve kalitesi de artmaktadır (Çakmakçı ve Tıngır 2001). Sağlam (1996), şeker pancarında hasat zamanının Ekim ayının ikinci yarısı olduğunu, kökgövde ve şeker veriminin hasat tarihi geciktikçe arttığını, kökgövde verimini etkileyen faktörlerin şeker verimini de etkilediğini ve şeker verimi ile kök gövde verimi arasında doğrusal bir ilişkinin olduğunu belirtmiştir.

\section{Sonuç}

Erzurum şartlarında şeker pancarında uygun hasat zamanının belirlenmeyi amaçladığımız bu çalışmada kök-gövde verimi en yüksek kasım ayının ilk haftası yaptığımız 3.hasat tarihinden 856 nolu genotipten, şeker verimi ise yine kasım ayının ilk haftası yaptığımız 3. hasat tarihinden 856 nolu genotipten, en yüksek kuru madde oranın ise ekim ayının üçüncü haftası yapmış olduğumuz 2. hasat tarihinden 546 ve 881 nolu genotipten elde edilmiştir. Araştırma sonuçlarımıza göre Erzurum koşullarında şeker pancarında uygun hasat tarihi olarak Kasım ayının ilk haftası ön plana çıkmıştır.

\section{Kaynaklar}

Ada R., Akınerdem F., 2011. Farklı zamanlarda hasat edilen şeker pancarında (Beta vulgaris saccharifera L.) verim, kalite ve hasat kayıplarının belirlenmesi, Selçuk Tarım ve Gıda Bilimleri Dergisi, 25 (1), 17-25

Akınerdem F., Sade B., Acar R., Soylu S., 1996. Konya şartlarında şeker pancarının (Beta vulgaris L.) hasat zamanının belirlenmesi. Tubitak-Doğa Dergisi 20 : 139-143

Anonim 2014. Erzurum İli İklim Kayıtları. Erzurum Meteoroloji İşleri Müd. Erzurum

Anonim 2014. FAO Kayıtları. http://www.tuik.gov.tr/ PreÇizelge.do?alt_id=1001

Bilgin Y., 1987b. Şeker Pancarı Tarımında Vejetasyon Seyrinin Verim ve Kaliteye Etkisi. 1. Ulusal Şeker Pancarı Üretimi Sempozyumu. Türkiye Şeker Fabrikaları A.Ş. Etimesgut, Ankara

Bürcky K. ve Minner C., 1986. The Influence of stand density of yield and quality of sugar beet of different harvesting dates.Journal of Agronomy and Crop Science. 1571 (4) : 264-272

Çakmakçı R. ve Tıngır N., 2001. Vejetasyon periyodu uzunluğunun şeker pancarının gelişim verim ve kalitesi üzerine etkisi. Atatürk Üniv. Zir. Fak. Derg. 32 (1), 41-49

Çatal M.İ., 2013. Konya Koşullarında Bazı Şeker Pancarı Çeşitlerinin Verim Ve Kalite Özelliklerinin Belirlenmesi, (Yüksek Lisans Tezi), Selçuk Üniversitesi Ziraat Fakültesi

Gencer O., 1988. Genel Tarla Bitkileri (Endüstri Bitkileri). Çukurova Üniv. Ziraat Fak., Ders Kitabı, No:42, Adana

Held L.J., Burgener P.A., Lauer J.G. ve Menkhaus D.L., 1994. An Economic analysis of reducing nitrogen on early harvest sugarbeets. J. Prod. Agric. 7 (4) : 422-428

Jozefyová L., Pulkrábek J. and Urban J., 2003. The Influence of harvest date and crop treatment on the production of two different sugar beet variety types. Plant Soil Environ., 49 (11) : 492-498

Jozefyova L., Pulkrabek J., and Urban J., 2004. Effect of harvest time on sugar beet fertilised with Increased nitrogen. Food, Agriculture \& Environment, 2 (1) : 232-237

Kurtcebe Ş., 1999. Göller Yöresine Uygun Monogerm Şeker Pancarı Çeşitlerinin Belirlenmesi. Süleyman Demirel Üniversitesi Fen Bilimleri Enstitüsü (Yüksek Lisans Tezi) Isparta

Öztürk Ö., Topal A., Akınerdem F., ve Akgün N., 2008. Effect of sowing and harvesting dates on yield and some quality characteristics of crops in sugar beet/cereal rotation system. J. Sci. Food Agric. $88: 141-150$ 
Radivogeviç S. ve Ivaz D., 1985. The Effect of harvesting time on quality of sugar beet. Field Crop Abstr., 38 (1) : 40

Radivojevic S.D. and Dosenovic I.R., 2006. Varietal and environmental influence on the yield and the end-use quality of sugar beet. APTEFF, $37: 1$ 192

Sağlam G., 1996. Burdur İlinin Dört Ayrı Ekim Bölgesinde Şeker Pancarının Vejetasyon Süresince Bazı Agronomik ve Kalite Özellikleri Üzerine Araştırma. Akdeniz Üniversitesi Fen Bilimleri Enstitüsü Yüksek Lisans Tezi, Antalya

Sefaoğlu F., Kaya C., Karakuş A., 2014. Erzurum Ekolojik Şartlarında Bazı Şeker Pancarı Genotiplerinin (Beta vulgaris saccharifera L.) Hasat Tarihi İle Ekonomik Parametreleri Arasındaki İlişkinin belirlenmesi. Enerji Tarımı ve Biyoyakıtlar 4. Ulusal Çalıştayı. 28-29 Mayıs 2014 Samsun. sf 169-177
Tayfur H., Abacı A.Y., 2002. Ekim Mevsimi ve Söküm Tarihinin Şeker Pancarı Çeşitlerinin Verim ve Kalitesi Üzerine Etkisi. İkinci Ulusal Şeker Pancarı Üretimi Sempozyumu, Bildiri Kitabı Sayfa 393-401, 10-11 Eylül, Ankara

Turgut T., 2012. Çeşit ve Lokasyon Farklılıklarının Şeker Pancarı (Beta vulgaris saccharifera L.)'nın Verim ve Kalite Özelliklerine Etkilerinin Araştırılması, (Yüksek Lisans Tezi), Namık Kemal Üniversitesi Ziraat Fakültesi

Ülker R., Koç H., Gümüşçü G., TopaL İ., Değer T., Karasu A., 2013. Konya Koşullarında Bazı Şeker Pancarı (Beta vulgaris L.) Çeşitlerinin Verim ve Kalite Özelliklerinin Belirlenmesi, Türkiye 10. Tarla Bitkileri Kongresi, Konya, 2.Kitap Sayfa:90-9

Ülgen N. ve Yurtsever N., 1984. Türkiye Gübre ve Gübreleme Rehberi. Toprak Su Genel Müdürlüğü Araştırma Dairesi Başkanlığı, Yayın No: 47, Ankara 